\title{
Association of FCGR2A/FCGR3A variant rs2099684 with Takayasu arteritis in the Han Chinese population
}

\author{
Si Chen ${ }^{1,2, *}$, Xiaoting Wen ${ }^{1, *}$, Jing $\mathrm{Li}^{1, *}$, Yuan $\mathrm{Li}^{1}$, Liubing Li ${ }^{1}$, Xinping Tian ${ }^{1}$, Hui \\ Yuan ${ }^{2}$, Fengchun Zhang ${ }^{1}$ and Yongzhe $\mathrm{Li}^{1}$ \\ ${ }^{1}$ Department of Rheumatology and Clinical Immunology, Peking Union Medical College Hospital, Chinese Academy of Medical \\ Sciences \& Peking Union Medical College, Key Laboratory of Rheumatology and Clinical Immunology, Ministry of Education, \\ Beijing, China \\ ${ }^{2}$ Department of Clinical Laboratory, Beijing Anzhen Hospital, Capital Medical University, Beijing, China \\ * These authors have contributed equally to this work
}

Correspondence to: Yongzhe Li, email: yongzhelipumch@126.com

Keywords: Takayasu arteritis, FCGR2A/FCGR3A, rs2099684, Chinese, Han

Received: April 12, $2016 \quad$ Accepted: October 14, $2016 \quad$ Published: October 18, 2016

\section{ABSTRACT}

Takayasu arteritis (TA) is a chronic large-vessel vasculitis of unclear pathogenesis. A recent genome-wide association study (GWAS) has revealed that the FCGR2A/FCGR3A, EEFSEC, RPS9/LILRB3, RIPPLY2 and MLX genes confer susceptibility to TA. We investigated the linkage between presumptive TA-related genes (FCGR2A/FCGR3A, EEFSEC, RPS9/LILRB3, RIPPLY2 and MLX) and TA in the Han Chinese population.

We performed a large case-control multi-center study of 412 Han Chinese TA patients and 597 ethnically matched healthy controls. Five single nucleotide polymorphisms (SNPs) were assessed and genotyped using Sequenom MassArray system (iPLEX assay, Sequenom, San Diego, CA, USA).

The frequency of the rs2099684 variant G allele in the FCGR2A/FCGR3A gene was significantly higher in the TA patients than in the controls ( $37.5 \%$ compared with $25.4 \%$, OR $\left.=1.77,95 \% \mathrm{CI}: 1.46-2.14, \mathrm{Pc}=1.5 \times 10^{-8}\right)$. Similar results were observed in genotype distribution analysis and logistic regression analyses conducted using three genetic models. The allele and genotype distributions for the other polymorphisms were not significantly associated with TA among the Han Chinese patients.

The SNP rs2099684 in FCGR2A/FCGR3A can be considered a genetic risk factor for TA in the Chinese Han population. These findings provide further insights into the etiopathogenesis of TA.

\section{INTRODUCTION}

Takayasu arteritis (TA) is a rare inflammatory disease typically characterized by non-specific inflammation of large arteries, especially the aorta and its major branches [1-3]. TA patients develop a wide range of symptoms, such as arterial stenosis, blood vessel wall thickening, dilation, progressive occlusion, and fibrosis, resulting in potentially life-threatening ischemia, aortic regurgitation, and pulselessness [1-3]. Other systemic symptoms may include myalgia, fatigue, arthralgia, fever, and weight loss. TA occurs all over the world and affects individuals of all ethnicities, but the highest prevalence rates have been described in Far East Asia,
India, and Mexico, and this disease appears to be less common in European-derived individuals. Its reported incidence in North America is 2.6 cases per million per year [4]. However, its estimated incidence in Japan is approximately 40 cases per million [5]. Furthermore, the actual prevalence of this disease is unknown, as no large-scale epidemiological survey has been performed in China. TA is much more common in women, but the extent of this sex bias is dependent upon ethnicity and regional location $[6,7]$. In addition, the average age of onset of this disease is between 20 and 40 years $[6,8]$.

The pathogenesis of TA has long been studied, but its etiology is largely unknown. The characteristic clinical features of TA, including the racial, ethnic, and geographic 
Table 1: Clinical data for TA patients and controls.

\begin{tabular}{lll}
\hline Characteristic & Case & Control \\
\hline Number of subjects & 412 & 597 \\
Female ratio $(\%)$ & 85.0 & 85.3 \\
Average age & $31.6 \pm 10.8$ & $36.2 \pm 10.2$ \\
Age at onset & $27.2 \pm 9.6$ & NA \\
Onset age $<20$ years & $85(20.6 \%)$ & NA \\
Hypertension & $94(22.8 \%)$ & NA \\
Coronary artery involvement & $11(2.7 \%)$ & NA \\
Ischemic brain disease & $67(16.3 \%)$ & NA \\
Renal artery stenosis & $111(26.9 \%)$ & NA \\
Pulmonary artery & $50(12.1 \%)$ & NA \\
involvement & & \\
Aortic regurgitation* & $55(23.9 \%)$ & NA \\
\hline I Only patients of Beijing Union Medical College Hospital were \\
analyzed on aortic regurgitation for detailed clinical data available.
\end{tabular}

differences, indicate a potential role of genetic factors in its pathogenesis. In fact, several lines of evidence suggest a genetic contribution to TA considering the ethnic differences in its prevalence, familial aggregation, cellular autoimmunity and genetic factors, especially the repeatedly confirmed genetic association with the human leukocyte antigen (HLA) region across multiple ethnicities [9-16]. $H L A-B * 52$ is the gene most significantly associated with TA in the $H L A$ region among TA patients. SaruhanDireskeneli et al. conducted a genome-wide association study (GWAS) of TA, in which they assessed Turkish and North American TA patients by dense genotyping and imputation analysis [17]. This group confirmed that the most significant genetic association was in the HLA region. In addition, they identified a genetic association in the region that includes the genes encoding $\mathrm{Fc}$ gamma receptor IIA (FCGR2A) and Fc-gamma receptor IIIA $(F C G R 3 A)$, as well as two additional association effects of proteasome (prosome, macropain) assembly chaperone 1 (PSMG1), interleukin-12 (IL-12) and IL$23(I L 12 B)$ that conferred a risk of TA but did not pass the threshold for genome-wide significance. Moreover, associations with the same genetic variants in $I L 12 B$ have been described and confirmed in a Japanese cohort of TA patients [18]. This group also discovered other non-HLA gene loci, including EEFSEC (rs10934853), CCHCR1 (rs9263739), RIPPLY2 (rs1570843) and MLX (rs665268) that conferred susceptibility to TA. Similarly, Renauer et al. carried out a GWAS on Turkish and North American TA patients and found that IL6 (rs2069837), RPS9/LILRB3 (rs11666543) and an intergenic locus on chromosome $21 \mathrm{q} 22$ (rs2836878) were associated with the disease [19].

It is widely accepted that racial and geographic differences and population heterogeneity are responsible for genetic predispositions to different diseases. The primary GWAS and candidate gene association studies were conducted on Turkish, North American and Japanese
TA patients [17-19]. Thus, it is important to examine the relationships of the candidate genes with TA in the Han Chinese population. In the current study, we investigated gene polymorphisms in FCGR $2 A / F C G R 3 A$, EEFSEC, RPS9/LILRB3, RIPPLY2 and MLX in 412 Han Chinese TA patients and 597 ethnically matched healthy individuals to evaluate the genetic factors associated with TA in this population.

\section{RESULTS}

\section{The subjects' characteristics}

A total of 412 adult-onset TA patients $(85.0 \%$ women; mean age, $31.6 \pm 10.8$ years) and 597 ethnically matched healthy controls $(85.3 \%$ women; mean age, $36.2 \pm 10.2$ years) were included in this study. The characteristics of the patients and controls are summarized in Table 1. All SNPs were in HWE in the healthy controls $\left(\mathrm{P}_{\mathrm{HWE}}>0.05\right)$. The genotype call rates of all SNPs were greater than $98 \%$. The primary information for the five genotyped SNPs is shown in Table 2.

\section{SNP analysis of the TA patients and controls from the Han population}

The genotype and allele frequency distributions of the five SNPs are summarized in Table 3. The frequency of the rs2099684 variant $\mathrm{G}$ allele was significantly higher in the TA patients than in the controls $(37.5 \%$ compared with $25.4 \%, \mathrm{OR}=1.77,95 \%$ CI: $1.46-2.14, \mathrm{Pc}=1.5 \times 10^{-8}$, Table 3). Similarly, a significant difference in the genotypic distribution of rs2099684 was detected between the TA patients and controls $\left(\mathrm{Pc}=4.9 \times 10^{-7}\right.$, Table 3$)$. However, 
Table 2: Primary information for these SNPs.

\begin{tabular}{|c|c|c|c|c|c|}
\hline Genotyped SNPs & rs2099684 & rs10934853 & rs11666543 & rs1570843 & rs665268 \\
\hline Gene & $F C G R 2 A / F C G R$ & EEFSEC & RPS9/LILRB3 & RIPPLY2 & $M L X$ \\
\hline Polymorphism & $\begin{array}{l}3 A \\
\mathrm{~A}>\mathrm{G}\end{array}$ & $\mathrm{C}>\mathrm{A}$ & $\mathrm{G}>\mathrm{A}$ & $\mathrm{T}>\mathrm{C}$ & $\mathrm{G}>\mathrm{A}$ \\
\hline Chromosome & 1 & 3 & 19 & 6 & 17 \\
\hline Function & Intergenic & intron region & nearGene-3 & intergenic & missense \\
\hline Chr Pos (NCBI) & 161530340 & 128319530 & 54208113 & 83810801 & 42570011 \\
\hline MAF for Chinese in database* & 0.36 & 0.39 & 0.10 & 0.49 & 0.40 \\
\hline MAF in our controls $(n=968)$ & 0.25 & 0.45 & 0.11 & 0.48 & 0.39 \\
\hline $\begin{array}{l}P c \text { for HWE test in our } \\
\text { controls }\end{array}$ & 0.45 & 0.16 & 0.13 & 0.32 & 0.86 \\
\hline Genotyping method & Sequenom & Sequenom & Sequenom & Sequenom & Sequenom \\
\hline Genotyping value $(\%)$ & $\begin{array}{l}\text { MassArrav } \\
100.0\end{array}$ & $\begin{array}{l}\text { MassArrav } \\
99.9\end{array}$ & $\begin{array}{l}\text { MassArrav } \\
98.3\end{array}$ & $\begin{array}{l}\text { MassArrav } \\
100.0\end{array}$ & $\begin{array}{l}\text { MassArrav } \\
99.8\end{array}$ \\
\hline
\end{tabular}

NCBI: National Center for Biotechnology Information; MAF: minor allele frequency; *: the data were from the International HapMap Project; HWE: Hardy-Weinberg equilibrium.

Table 3: Allele and genotype distribution of the gene markers in TA patients and controls.

\begin{tabular}{|c|c|c|c|c|c|c|c|c|c|c|c|c|c|}
\hline \multirow[t]{2}{*}{ Gene } & \multirow[t]{2}{*}{ SNPs } & \multirow[t]{2}{*}{ Groups } & \multicolumn{2}{|l|}{ Allele (\%) } & \multirow[t]{2}{*}{ OR $(95 \% \mathrm{CI})$} & \multirow[t]{2}{*}{$P$} & \multirow[t]{2}{*}{$P c$} & \multicolumn{3}{|c|}{ Genotype (\%) } & \multirow[t]{2}{*}{$\chi^{2}$} & \multirow[t]{2}{*}{$P$} & \multirow[t]{2}{*}{$P c$} \\
\hline & & & G & A & & & & GG & GA & AA & & & \\
\hline \multirow{4}{*}{$\begin{array}{l}F C G R 2 A \\
F C G R 3 A\end{array}$} & rs2099684 & $\mathrm{TA}$ & $309(37.5)$ & $515(62.5)$ & $1.77(1.46-2.14)$ & $3.0 \times 10^{-9}$ & $1.5 \times 10^{-8}$ & $67(16.3)$ & $175(42.5)$ & $170(41.2)$ & 32.27 & $9.8 \times 10^{-8}$ & $4.9 \times 10^{-7}$ \\
\hline & & & & & & & & & & & & & \\
\hline & & Controls & $303(25.4)$ & $891(74.6)$ & & & & $42(7.0)$ & $219(36.7)$ & $336(56.3)$ & & & \\
\hline & & & A & $\mathrm{C}$ & & & & $\mathrm{AA}$ & $\mathrm{CA}$ & $\mathrm{CC}$ & & & \\
\hline \multirow[t]{3}{*}{ EEFSEC } & rs 10934853 & TA & $344(41.8)$ & $478(58.2)$ & $0.90(0.75-1.07)$ & 0.22 & NS & $22(18.7)$ & $190(46.3)$ & $144(35.0)$ & 4.57 & 0.10 & 0.50 \\
\hline & & Controls & $533(44.6)$ & $661(55.4)$ & & & & $110(18.4)$ & $313(52.4)$ & $174(29.2)$ & & & \\
\hline & & & A & G & & & & $\mathrm{AA}$ & GA & GG & & & \\
\hline \multirow{4}{*}{$\begin{array}{l}\text { RPS9/LIL } \\
\text { RB3 }\end{array}$} & rs 11666543 & $\mathrm{TA}$ & $67(8.3)$ & $737(91.7)$ & $0.74(0.55-1.00)$ & 0.05 & 0.25 & $3(0.7)$ & $61(15.2)$ & $338(84.1)$ & $\mathrm{NA}^{*}$ & 0.08 & 0.40 \\
\hline & & & & & & & & & & & & & \\
\hline & & Controls & $129(10.9)$ & $1051(89.1)$ & & & & $3(0.5)$ & $123(20.8)$ & $464(78.7)$ & & & \\
\hline & & & $\mathrm{C}$ & $\mathrm{T}$ & & & & $\mathrm{CC}$ & $\mathrm{TC}$ & $\mathrm{TT}$ & & & \\
\hline \multirow[t]{3}{*}{ RIPPLY2 } & rs 1570843 & $\mathrm{TA}$ & $394(47.8)$ & $430(51.2)$ & $1.02(0.86-1.22)$ & 0.82 & NS & $98(23.8)$ & $198(48.1)$ & $116(28.1)$ & 1.61 & 0.45 & NS \\
\hline & & Controls & $569(47.7)$ & $625(52.3)$ & & & & $129(21.6)$ & $311(52.1)$ & $157(26.3)$ & & & \\
\hline & & & $\mathrm{G}$ & $\mathrm{A}$ & & & & GG & $\mathrm{AG}$ & $\mathrm{AA}$ & & & \\
\hline \multirow[t]{2}{*}{$M L X$} & rs 665268 & $\mathrm{TA}$ & $304(37.1)$ & $516(62.9)$ & $0.90(0.75-1.08)$ & 0.24 & NS & $62(15.1)$ & $180(43.9)$ & $168(41.0)$ & 1.99 & 0.37 & NS \\
\hline & & Controls & $467(39.1)$ & $727(60.9)$ & & & & $90(15.1)$ & $287(48.1)$ & $220(38.8)$ & & & \\
\hline
\end{tabular}

TA: takayasu arteritis; OR: odds ratio; CI: confidence interval; $\chi^{2}$ : Chi-square test; Pc: $P$ value corrected by Bonferroni method; NA: not available; NA*: the P value of genotypic analysis was calculated under the logistic regression analysis; NS: not significant.

no significant association with TA was detected for any of the other SNPs among the patients (all, Pc >0.05; Table 3). The logistic regression analysis results are summarized in Table 3. Logistic regression analyses based on the genetic additive, dominant and recessive models yielded similar results, with stronger associations between rs2099684 and TA observed using the additive model $(\mathrm{OR}=1.72$, 95\% CI: $\left.1.43-2.07, \mathrm{Pc}=7.4 \times 10^{-8}\right)$ and dominant model $\left(\mathrm{OR}=1.87,95 \% \mathrm{CI}: 1.46-2.40, \mathrm{Pc}=5.0 \times 10^{-6}\right)$. However, no significant differences were detected between the TA patients and healthy controls for the other SNPs using any of the three genetic models (all, Pc $>0.05$, Table 4).

\section{DISCUSSION}

In this large-scale hospital-based case-control study, we investigated the associations of FCGR2A/ 
Table 4: Analysis of the five SNPs based on three genetic models.

\begin{tabular}{|c|c|c|c|c|c|c|c|}
\hline \multirow{2}{*}{ Gene } & \multirow{2}{*}{ SNPs } & \multicolumn{2}{|c|}{ Additive model } & \multicolumn{2}{|c|}{ Dominant model } & \multicolumn{2}{|c|}{ Recessive model } \\
\hline & & $P c$ & OR $(95 \% C I)$ & $P c$ & OR $(95 \% \mathrm{CI})$ & $P c$ & OR $(95 \% \mathrm{CI})$ \\
\hline$F C G R 2 A / F C G R 3 A$ & rs2099684 & $7.4 \times 10^{-8}$ & $1.72(1.43-2.07)$ & $5.0 \times 10^{-6}$ & $1.87(1.46-2.40)$ & $4.9 \times 10^{-5}$ & $2.50(1.67-3.75)$ \\
\hline EEFSEC & rs10934853 & NS & $0.89(0.75-1.07)$ & 0.21 & $0.76(0.58-0.99)$ & NS & $1.03(0.75-1.42)$ \\
\hline RPS9/LILRB3 & rs11666543 & 0.25 & $0.96(0.78-1.20)$ & 0.17 & $0.70(0.51-0.97)$ & NS & $1.39(0.28-6.94)$ \\
\hline RIPPLY2 & rs1570843 & NS & $1.02(0.86-1.22)$ & NS & $0.92(0.70-1.22)$ & NS & $1.16(0.86-1.55)$ \\
\hline$M L X$ & rs665268 & NS & $0.90(0.75-1.08)$ & 0.59 & $0.82(0.63-1.05)$ & $\mathrm{NS}$ & $0.98(0.69-1.39)$ \\
\hline
\end{tabular}

OR odds ratio; CI confidence interval; Pc: $P$ value corrected by Bonferroni method; NS: not significant.

FCGR3A (rs2099684), EEFSEC (rs10934853), RPS9/ LILRB3 (rs11666543), RIPPLY2 (rs1570843) and MLX (rs665268) polymorphisms with the risk of TA in 412 Han Chinese TA patients and 597 ethnically matched healthy controls. Several gene variants associated with TA have been identified, but the three previous GWASs have been conducted on Turkish, North American and Japanese TA patients [17-19]. Therefore, further comparative studies are warranted to examine subjects of different ethnicities. The results of this study demonstrated a significant association between the FCGR2A/FCGR3A (rs2099684) polymorphism and TA among the patients. This result is consistent with previous findings reported for Turkish and North American TA patients [17]. Notably, this is the first study demonstrating a significant association between the FCGR2A/FCGR3A (rs2099684) polymorphism and susceptibility to TA in the Chinese Han population.

The rs2099684 locus is located between the $F C G R 2 A$ and FCGR3A gene regions on chromosome 1:161524048-161541759. The FCGR2A gene encodes one member of a family of immunoglobulin Fc receptors that are found on the surfaces of many immune response cells. The protein encoded by the FCGR $2 A$ gene is a cell surface receptor present on monocytes, macrophages, neutrophils, natural killer (NK) cells, and T- and B-lymphocytes, and it participates in diverse functions, such as phagocytosis of immune complexes and modulation of antibody production by $\mathrm{B}$ cells. In addition, it has important roles in the GPCR and phospholipase $\mathrm{C}$ pathways. The FCGR3A gene encodes a transmembrane receptor for the $\mathrm{Fc}$ portion of immunoglobulin $\mathrm{G}$ that is involved in the removal of antigen-antibody complexes from circulation, as well as other antibody-dependent responses. This receptor is expressed on activated monocytes/macrophages, NK cells, and a subset of T cells.

Previous studies have revealed that the prevalence of other inflammatory diseases in TA patients is high, suggesting that TA may be associated with immune system abnormalities activated by other inflammatory diseases, such as infection or inflammatory diseases of unknown origin [20]. FCGR2A/FCGR3A has been reported to be a susceptibility gene for other autoimmune diseases, such as systemic lupus erythematosus [21,
22], rheumatoid arthritis [23], multiple sclerosis [24], type 1 diabetes [23] and ulcerative colitis [25, 26]. In addition, a genetic association between the FCGR2A/ FCGR3A polymorphism and giant cell arteritis (GCA) has been previously identified in a small cohort from Spain [27]. The findings of these studies indicate that these two large-vessel vasculitides might share common predisposing genes. Previously, GCA and TA have been considered distinct disorders based on their differing ages of onset and ethnic distributions. However, reports have claimed that these disorders have more similarities than differences, including similarities in several clinical features, angiographic findings, and the histopathological characteristics of arterial lesions $[28,29]$. Thus, our results indicate that $F C G R 2 A / F C G R 3 A$ might be a susceptibility gene for TA in patients from the Chinese Han population, suggesting that TA might share associated genetic loci with other autoimmune diseases.

The EEFSEC (rs10934853), RPS9/LILRB3 (rs11666543), RIPPLY2 (rs1570843) and MLX (rs665268) polymorphisms were not found to be significantly associated with TA among the Chinese patients in our study, in contrast with the findings of previous studies. These inconsistencies in the results among studies may be due to differences in these loci between CEU (Utah residents with ancestry from Northern and Western European sample), JPT (Japanese in Tokyo, Japan) and CHB (Han Chinese in Beijing, China) in terms of linkage disequilibrium structure and minor allele frequency, and they may also be attributed to heterogeneous patient populations with racial and geographical differences. Therefore, the genetics of TA may be more complicated than previously thought. Additional studies of subjects of different ethnicities might elucidate whether SNPs in the EEFSEC, RPS9/LILRB3, RIPPLY and MLX genes are associated with susceptibility to TA.

Because TA is a rare autoimmune disease, early candidate gene studies only included small numbers of patients to increase statistical power. In some early studies, patients of different ethnicities were even investigated together. To avoid this limitation, our study enrolled a larger number of TA patients from the Chinese Han population than the early candidate gene 
studies. Therefore, the present investigation had sufficient statistical power to examine moderate and even marginal associations. Remarkably, our study revealed a significant positive association between the FCGR $2 A / F C G R 3 A$ (rs2099684) polymorphism and TA among the Chinese Han patients. Therefore, this SNP may play a potential role in the pathogenesis of TA. Nevertheless, we did not assess the role of the FCGR2A/FCGR3A (rs2099684) genetic variant in the development of TA in these patients.

In summary, the results of this study have demonstrated a strong relationship between the FCGR2A/ FCGR3A (rs2099684) polymorphism and TA in patients from the Chinese Han population. These findings have provided supportive evidence and contribute to current knowledge about the pathogenesis of TA. Further investigations are needed to explore the associations of EEFSEC, RPS9/LILRB3, RIPPLY and MLX with TA in individuals of different ethnicities and from different regions.

\section{MATERIALS AND METHODS}

\section{Subjects}

This study was designed as a multi-center study that included 412 subjects with TA, diagnosed according to the American College of Rheumatology (ACR) criteria [30]. These patients were enrolled from two different sources; between February 2013 and July 2015, 230 patients were enrolled from the Peking Union Medical College Hospital. In addition, as this study was supported by the Research Special Fund for Public Welfare Industry of Health, 182 patients were recruited through the cooperation of 23 centers in China. Further, 597 healthy unrelated ageand sex-matched controls without any history of chronic disease were recruited from the Peking Union Medical College Hospital during physical examination. All patients and healthy individuals from the Chinese Han population of North China provided informed consent, and this study was approved by the Ethics Committee of the Peking Union Medical College Hospital.

\section{Selection of single nucleotide polymorphisms (SNPs)}

Based on the findings of previous GWASs of TA patients, five SNPs (rs2099684, rs10934853, rs11666543, rs 1570843 and rs665268) in the FCGR $2 A / F C G R 3 A$, EEFSEC, RPS9/LILRB3, RIPPLY2 and MLX genes were selected for analysis in this study (Table 2 ).

\section{Genotyping}

We collected 2-mL peripheral blood samples from the TA patients and healthy controls and extracted DNA from the peripheral white blood cells of each participant using kits purchased from Tiangen (Beijing, China), according to the manufacturer's instructions. The genotyping of five SNPs was accomplished using a Sequenom MassArray system (Sequenom iPLEX assay, San Diego, CA, USA) according to the manufacturer's guidelines.

The primers for polymerase chain reaction (PCR) and for locus-specific single-base extension were designed using MassArray Assay Design 4.0 (Sequenom). First, all of the DNA samples from the patients and controls were transferred to a 384-well plate. Second, after multiplex PCR amplification, the products were used for locusspecific single-base extension reactions. Third, the final products were subsequently desalted and transferred to a 384-element SpectroCHIP array (Sequenom). Fourth, allele detection was performed by matrix-assisted laser desorption/ionization-time-of-flight mass spectrometry (MALDI-TOF MS). Finally, the resultant mass spectrograms and genotype data were analyzed using MassArray Typer 4.0 software.

\section{Statistical analysis}

Statistical analysis was conducted using PLINK v1.07 software (Shaun Purcell, Boston, MA, USA) [31]. Hardy-Weinberg equilibrium (HWE) was assessed using the Chi-square $\left(X^{2}\right)$ test for each SNP. Any SNPs that deviated from HWE $(P<0.05$ in the control groups) were excluded from subsequent analysis. The genotype and allele distributions between the TA patients and healthy controls were evaluated using the $X^{2}$ test. $P$-values (corrected for multiple comparisons using the Bonferroni method) of less than 0.05 were considered statistically significant, and the odds ratios (ORs) and 95\% confidence intervals (95\% CIs) of associations were calculated. The genotype frequencies were further assessed using logistic regression models (additive, dominant, and recessive models).

\section{ETHICAL STATEMENT}

The study was approved by the Ethics Committee of the Peking Union Medical College Hospital.

\section{ACKNOWLEDGMENTS}

We'd like to give our sincere appreciation and thanks to all the patients with TA, who made this study possible, to multiple centers in China for the use of TA sample and clinical data. 


\section{CONFLICTS OF INTEREST}

The authors declare that they have no conflict of interest.

\section{GRANT SUPPORT}

This study is supported by funding from the Research Special Fund for Public Welfare Industry of Health (201202004), and the National Natural Science Foundation of China Grants (81172857, 81373188), the Chinese National High Technology Research and Development Program, Ministry of Science and Technology Grants (2011AA02A113), the National Science Technology Pillar Program in the 12nd Five-year Plan (2014BAI07B00), and the Capital Health Research and Development of Special (2014-1-4011).

\section{REFERENCES}

1. Kobayashi $\mathrm{Y}$ and Numano F. Takayasu arteritis. Internal medicine. 2002; 41: 44-6. doi: 10.2169/ internalmedicine.41.44

2. Bicakcigil M, Aksu K, Kamali S, Ozbalkan Z, Ates A, Karadag O, Ozer HT, Seyahi E, Akar S, Onen F, Cefle A, Aydin SZ, Yilmaz N, et al. Takayasu's arteritis in Turkey clinical and angiographic features of 248 patients. Clinical and experimental rheumatology. 2009; 27: S59-64.

3. Kerr GS, Hallahan CW, Giordano J, Leavitt RY, Fauci AS, Rottem M, and Hoffman GS. Takayasu arteritis. Annals of internal medicine. 1994; 120: 919-29.

4. Hall S, Barr W, Lie JT, Stanson AW, Kazmier FJ, and Hunder GG Takayasu arteritis. A study of 32 North American patients. Medicine (Baltimore). 1985; 64: 89-99.

5. Isobe M. Takayasu arteritis revisited: current diagnosis and treatment. International journal of cardiology. 2013; 168 : $3-10$.

6. Johnston SL, Lock RJ, and Gompels MM. Takayasu arteritis: a review. Journal of clinical pathology. 2002; 55: 481-6.

7. Phillip R and Luqmani R. Mortality in systemic vasculitis: a systematic review. Clinical and experimental rheumatology. 2008; 26: S94-104.

8. Numano F. Hereditary factors of Takayasu arteritis. Heart and vessels. supplement. 1992; 7: 68-72.

9. Charoenwongse P, Kangwanshiratada O, Boonnam R, and Hoomsindhu U. The association between the HLA antigens and Takayasu's arteritis in Thai patients. International journal of cardiology. 1998; 66 (Suppl 1): S117-20.

10. Lee SW, Kwon OJ, Park MC, Oh HB, Park YB, Lee SK. HLA alleles in Korean patients with Takayasu arteritis. Clinical and experimental rheumatology. 2007; 25: S18-22.

11. Mehra NK, Jaini R, Balamurugan A, Kanga U, Prabhakaran D, Jain S, Talwar KK, and Sharma BK. Immunogenetic analysis of Takayasu arteritis in Indian patients. International journal of cardiology. 1998; 66: S127-32; discussion S133.

12. Sahin Z, Bicakcıgil M, Aksu K, Kamali S, Akar S, Onen F, Karadag O, Ozbalkan Z, Ates A, Ozer HT, Yilmaz V, Seyahi E, Ozturk MA et al. Takayasu's arteritis is associated with HLA-b*52, but not with HLA-b*51, in Turkey. Arthritis research and therapy. 2012; 14: R27.

13. Dong RP, Kimura A, Numano F, Nishimura Y, and Sasazuki T. HLA-linked susceptibility and resistance to Takayasu arteritis. Heart and vessels. 1992; 7: 73-80.

14. Lv N, Dang A, Wang Z, Zheng D, and Liu G. Association of susceptibility to Takayasu arteritis in Chinese Han patients with HLA-DPB1. Human immunology. 2011; 72: 893-6.

15. Dang A, Wang B, Zhang Y, Zhang P, Huang J, Liu G, Zheng D, Qiu C, and Liu L. Association of the HLA-DRB1 gene with susceptibility to aortoarteritis in a Chinese Han population. Hypertension research. 2002; 25: 631-4.

16. Lv N, Wang Z, Dang A, Zhu X, Liu Y, Zheng D, and Liu G. HLA-DQA1, DQB1 and DRB1 alleles associated with Takayasu arteritis in the Chinese Han population. Human immunology. 2015; 76: 241-4.

17. Saruhan-Direskeneli G, Hughes T, Aksu K, Keser G, Coit P, Aydin SZ, Alibaz-Oner F, Kamalı S, Inanc M, Carette S, Hoffman GS, Akar S, Onen F, et al. Identification of multiple genetic susceptibility loci in Takayasu arteritis. American journal of human genetics. 2013; 93: 298-305.

18. Terao C, Yoshifuji H, Kimura A, Matsumura T, Ohmura K, Takahashi M, Shimizu M, Kawaguchi T, Chen Z, Naruse TK, Sato-Otsubo A, Ebana Y, Maejima Y, et al. Two susceptibility loci to Takayasu arteritis reveal a synergistic role of the IL12B and HLA-B regions in a Japanese population. American journal of human genetics. 2013; 93: 289-97.

19. Renauer PA, Saruhan-Direskeneli G, Coit P, Adler A, Aksu K, Keser G, Alibaz-Oner F, Aydin SZ, Kamali S, Inanc M, Carette S, Cuthbertson D, Hoffman GS, et al. Identification of susceptibility loci in IL6, RPS9/LILRB3, and an Intergenic locus on Chromosome 21q22 in Takayasu arteritis in a genome-Wide Association Study. Arthritis rheumatol. 2015; 67: 1361-8.

20. Ohta Y, Ohya Y, Fujii K, Tsuchihashi T, Sato K, Abe I, and Iida M. Inflammatory diseases associated with Takayasu's arteritis. Angiology. 2003; 54: 339-44.

21. Salmon JE, Millard S, Schachter LA, Arnett FC, Ginzler EM, Gourley MF, Ramsey-Goldman R, Peterson MG, and Kimberly RP. Fc gamma RIIA alleles are heritable risk factors for lupus nephritis in African Americans. Journal of clinical investigation. 1996; 97: 1348-54.

22. Harley JB, Alarcon-Riquelme ME, Criswell LA, Jacob CO, Kimberly RP, Moser KL, Tsao BP, Vyse TJ, Langefeld CD, Nath SK, Guthridge JM, Cobb BL, Mirel DB, et al. Genome-wide association scan in women with systemic 
lupus erythematosus identifies susceptibility variants in ITGAM, PXK, KIAA1542 and other loci. Nature genetics. 2008; 40: 204-10.

23. Alizadeh BZ, Valdigem G, Coenen MJ, Zhernakova A, Franke B, Monsuur A, van Riel PL, Barrera P, Radstake TR, Roep BO, Wijmenga C, and Koeleman BP. Association analysis of functional variants of the FcgRIIa and FcgRIIIa genes with type 1 diabetes, celiac disease and rheumatoid arthritis. Human molecular genetics. 2007; 16: 2552-9.

24. Takai T. Roles of Fc receptors in autoimmunity. Nature reviews. immunology. 2002; 2: 580-92.

25. Asano K, Matsushita T, Umeno J, Hosono N, Takahashi A, Kawaguchi T, Matsumoto T, Matsui T, Kakuta Y, Kinouchi Y, Shimosegawa T, Hosokawa M, Arimura Y, et al. A genome-wide association study identifies three new susceptibility loci for ulcerative colitis in the Japanese population. Nature genetics. 2009; 41: 1325-9.

26. McGovern DP, Gardet A, Törkvist L, Goyette P, Essers J, Taylor KD, Neale BM, Ong RT, Lagacé C, Li C, Green T, Stevens CR, Beauchamp C, et al. Genome-wide association identifies multiple ulcerative colitis susceptibility loci. Nature genetics. 2010; 42: 332-7.

27. Morgan AW, Robinson JI, Barrett JH, Martin J, Walker A, Babbage SJ, Ollier WE, Gonzalez-Gay MA, and Isaacs JD. Association of FCGR2A and FCGR2A-FCGR3A haplotypes with susceptibility to giant cell arteritis. Arthritis research and therapy. 2006; 8: R109.
28. Maksimowicz-McKinnon K, Clark TM, and Hoffman GS. Takayasu arteritis and giant cell arteritis: a spectrum within the same disease? Medicine (Baltimore). 2009; 88: 221-6.

29. Grayson PC, Maksimowicz-McKinnon K, Clark TM, Tomasson G, Cuthbertson D, Carette S, Khalidi NA, Langford CA, Monach PA, Seo P, Warrington KJ, Ytterberg SR, Hoffman GS, et al. Distribution of arterial lesions in Takayasu's arteritis and giant cell arteritis. Annals of the rheumatic diseases. 2012; 71: 1329-34.

30. Arend WP, Michel BA, Bloch DA, Hunder GG, Calabrese LH, Edworthy SM, Fauci AS, Leavitt RY, Lie JT, Lightfoot RW, Masi AT, McShane DJ, Mills JA, et al. The American College of Rheumatology 1990 criteria for the classification of Takayasu arteritis. Arthritis and rheumatism. 1990; 33: 1129-34.

31. Skol AD, Scott LJ, Abecasis GR, and Boehnke M. Joint analysis is more efficient than replication-based analysis for two-stage genome-wide association studies. Nature genetics. 2006; 38: 209-13. 